\title{
REFLEXÕES A RESPEITO DOS PROCESSOS DE JUDICIALIZAÇÃO E CRIMINALIZAÇÃO NO CONTROLE DA CONTEMPORANEIDADE
}

\author{
Cristiane Freitas da Silva \\ Universidade Federal do Pará - UFPA - Brasil
}

Flávia Cristina Silveira Lemos

Universidade Federal do Pará - UFPA - Brasil

José de Araújo Brito Neto

Universidade Federal do Pará - UFPA - Brasil

Michelle Ribeiro Côrrea

Universidade Federal do Pará - UFPA - Brasil

Amanda Pereira de Carvalho Cruz

Universidade Federal do Pará - UFPA - Brasil

Paulo de Tarso Ribeiro de Oliveira

Universidade Federal do Pará - UFPA - Brasil

\section{Resumo}

As práticas de recurso ao Judiciário, para lidar com as tensões, têm-se expandido, nas últimas décadas, em um processo de judicialização e criminalização da vida. Assinalamos uma relação entre sociedade e Poder Judiciário pautada na busca de ampliação das leis e tipificações penais como maneiras de governar condutas, no campo de um legalismo securitário. O Poder Judiciário parece converter-se em uma espécie de arena única para a qual converge toda sorte de tensão e desentendimento, e as leis, assim, transformam-se na linguagem dessa mediação. Porém, abordamos igualmente uma descrição e análise histórica 
que opera pela normalização da lei, nos tribunais da norma. Desse modo, buscamos, nesta breve análise, refletir sobre tais questões, propondo analisar esses dispositivos de controle que se intensificam na atualidade e que provocam novas formas de assujeitamento.

Palavras-chave: Judicialização e Criminalização. Leis e penas. Segurança e controle. Poder soberano. Tribunal das normas.

\section{Introdução}

Neste artigo, pretendemos apresentar brevemente um debate atual e preocupante, a nosso ver, chegando a assinalar um aspecto intolerável do tempo presente, que é a judicialização, a criminalização e a normalização da vida baseada na racionalidade da segurança. Dessa maneira, interrogar as práticas que vêm sendo encomendadas ao Poder Judiciário pela sociedade e vice-versa é um objeto de preocupação neste texto. Também nos inquieta o destaque que vem sendo dado ao Poder Judiciário em relação aos três poderes do Estado Democrático de Direito, em que este ganhou mais relevância do que o Executivo e o Legislativo.

Uma sociedade punitiva se amplia por meio da relação judicializante da vida; todavia, ela igualmente se materializa na normalização do Direito e na expansão intensiva da lógica de tribunais para as relações cotidianas de nossa sociedade. Nesse sentido, Michel Foucault (1999) observou que as escolas, as famílias, as fábricas, os hospitais, se parecem com as prisões e estas se assemelham às outras. Obviamente, há diferenças entre elas, porém, há práticas vizinhas em efeitos recíprocos.

Michel Foucault é um interlocutor importante e que traz contribuições relevantes para pensar a sociedade contemporânea, sobretudo as práticas punitivas, porque ele pontuou algo a que poucos prestam atenção, no debate a respeito do encarceramento em massa e na ampliação da racionalidade penal. Para Foucault (1996; 1999; 2008a; 2008b), a punição é mais ampla que a pena, pois a penalidade imputada pelos princípios do Direito Penal é apenas um dos aspectos de uma sociedade baseada na aposta da segurança e da punição como maneira de gerir a vida. Assim, Foucault nos auxilia a pensar a relação entre lei e norma, em efetuação em outros equipamentos sociais para além da prisão e da pena.

\section{Processos de judicialização da vida}

A judicialização da vida constitui um processo do/no contemporâneo, em que o Poder Judiciário tem recebido mais destaque do que o Legislativo e Executivo, no plano das 
decisões federais do Estado e de relevância social. O Supremo Tribunal Federal se tornou instância final de recurso diante das mais diversas encomendas da sociedade. Acompanhamos certa impotência do Legislativo e do Executivo, frente a uma busca social contemporânea de transformar as tensões em disputas jurídicas.

Essa prática, apesar de ser acompanhada e gerar efeitos vizinhos à judicialização, dela difere, o que implica algo mais amplo que as relações entre os três poderes na esfera federal, em termos da composição do Estado chamado Democrático de Direito. A judicialização ocorre atrelada à difusão do recurso ao Poder Judiciário para mediar, regrar e punir os efeitos dos desacordos nos contratos do cotidiano das existências, no plano das normas sociais também. Não se trata apenas de mera "intromissão" do Judiciário em nossas vidas, já que ele ocorre por encomendas de diferentes atores sociais, por transformarmos as nossas relações, que poderiam ser de forma mais direta, em relações terceirizadas, por meio das figuras do juiz, do advogado, dos promotores, entre outros operadores jurídicos.

Obviamente, a ideia não é aniquilar ou destruir a macropolítica do Poder Judiciário em nossas vidas, mesmo porque a questão não é essa. Trata-se, na verdade, de questionarmos o motivo de nossas relações estarem tão judicializadas e o que podemos fazer para que realmente estejamos falando e afirmando a vida, em outras esferas e equipamentos.

O processo de judicialização da vida compreende um movimento no qual o Poder Judiciário se torna a instituição mediadora do viver. Essa ampliação do domínio jurídico temse estendido por espaços antes habitados por outros saberes e práticas, capilarizando a função do tribunal às diversas esferas do cotidiano. A judicialização se dá porque se acredita e se teme a lei e porque se busca pautar a vida pela vingança sustentada na retribuição de danos.

A lei e a punição que reivindica reparação de danos se tornam a referência para atuar, dificultando saídas singulares e inventivas. A sociedade contemporânea criou uma maquinaria jurídica sem igual: os juízes, os promotores e os defensores públicos e advogados são profissionais que a todo o momento são acionados. Os discursos recorrentes dão conta de que as leis devem ser utilizadas com rigor e, em geral, são vistas como sendo insuficientes para os que clamam pelo recrudescimento penal.

Nesse cenário, uma das encomendas mais reivindicadas é a criação de mais e mais leis, uma proliferação legalista e punitiva. Porém, mais que isso, a máquina jurídica se multiplica nas ações cotidianas. O Poder Judiciário parece converter-se em uma espécie de arena única, para a qual convergem os pedidos marcados por dores e dramas variados, os quais são reduzidos em sua complexidade em nome da vingança reativa do Direito Positivo Penal e Retributivo. 
A judicialização é um acontecimento que marca as últimas décadas do século XX e os primeiros anos do século XXI, manifestando-se nas democracias representativa e participativa, embora de modo heterogêneo em ambas. Podemos destacar que também é regularmente apresentada no contexto da crise do Estado de Bem-estar, todavia, suas condições de possibilidade são singulares.

Boaventura de Souza Santos (1996) relata que o protagonismo do Judiciário nas democracias contemporâneas, ao menos quando tratamos dos países do hemisfério norte, não é um acontecimento tão recente. Estamos falando em termos de soberania jurídica, nesse caso, e não de analítica do poder, apenas para demarcar as maneiras de problematizar as práticas de poder. Foucault (1979) ressalta que o poder soberano é localizado no Estado e em seus aparelhos de justiça e governo, baseados no direito administrativo público comercial e penal. Contudo, ele assinala que há outros modos de descrever e pensar as relações de poder, sem localizá-las e sem tratá-las como algo que se cede e que se transfere.

Voltando a Boaventura (1996), este declara que a diferença do comportamento dos tribunais no passado era o alto grau de conservadorismo observado, além do fato de suas intervenções se processarem muito mais de modo esporádico, em momentos de transformação social e política intensa. De semelhanças com o presente, aponta para o atual protagonismo que guarda em comum com o anterior um confronto com a classe política e com outros órgãos de poder soberano, nomeadamente com o Poder Executivo, por isso a constância do tema da judicialização da política.

Prado Filho (2012) pondera que a justiça deixa de ser litígio particular entre indivíduos para ser problema de manutenção de soberania: os conflitos não mais serão negociados e resolvidos entre os envolvidos, mas estes terão agora que se submeter à regulação de um Poder Judiciário que passou a ser organizado como poder político.

De acordo com Boaventura de Souza Santos (1996), tomando-se os últimos 150 ou 200 anos, é possível marcar três momentos na história da postura sociopolítica dos tribunais: o primeiro corresponde ao período do Estado Liberal, o segundo equivale ao do Estadoprovidência e o terceiro à crise do Estado-providência.

O primeiro período, o qual se estende por todo o século XIX até a Primeira Guerra Mundial, no século XX, é caracterizado por uma rigorosa separação entre os três poderes clássicos, sendo o Judiciário um poder politicamente neutralizado. O segundo período tem início ainda no fim do século XIX, quando as estruturas político-jurídicas começam a se alterar, mas é definitivamente caracterizado somente após a Segunda Guerra Mundial, quando da constituição do Estado do Bem-Estar Social. 
O terceiro momento começa no século XX, nos fins da década de 1970 e princípios dos anos 1980, quando se manifestam nos países considerados centrais os primeiros sinais de crise do Estado-providência. A atividade sociopolítica dos tribunais é caracterizada, nesse momento, por uma radicalização da judicialização verificada no período anterior. Boaventura Souza Santos chega a relacionar dois importantes acontecimentos que têm contribuído para o processo descrito: em primeiro lugar, a desregulamentação da economia trazida pelo neoliberalismo, que de fato acaba por explicitar uma "re-regulamentação", pois a "desregulamentação", em muitos casos só foi possível mediante uma sobrecarga legislativa adicional; e, em segundo lugar, está. a globalização da economia, fomentando igualmente uma inflação legislativa.

Outra característica do período é a emergência de uma legalidade baseada em normas programáticas, cujo conteúdo indeterminado tem dado origem ao surgimento de litígios altamente complexos. Ademais, aparecem nesse período novas áreas de litígio, como as da proteção ao meio ambiente e ao direito do consumidor, as quais passam, progressivamente, a fazer parte da agenda dos movimentos sociais e para as quais em geral os tribunais apresentam pouca preparação técnica.

Investigando também a emergência do processo de judicialização no mundo contemporâneo, Cappelletti alude a outros efeitos do estabelecimento do Estado do Bem-estar sobre o direito e sobre a função do magistrado. $\mathrm{O}$ autor parte da constatação de que os juízes têm sido crescentemente chamados a atuar de modo mais criativo, nos tribunais, rompendo com o conceito clássico de Montesquieu, que os apresentava como "boca inanimada da lei". A intensificação da atuação "mais criativa dos juízes" seria resultante de uma espécie de "revolta contra o formalismo", expressa em várias escolas do pensamento jurídico que rompiam com o formalismo clássico (CAPPELLETTI, 1993).

No Brasil, o processo de judicialização é contextualizado, sobretudo após a promulgação da Constituição de 1988, que trouxe para ordem do dia o tema dos direitos da cidadania e da renascente ordem democrática. Luiz Werneck Vianna (1997; 1999), focando o caso brasileiro, aborda dois acontecimentos, que, embora sejam partes de um mesmo contexto, traduzem ideias um pouco distintas: por "judicialização da política" entende-se o "processo por meio do qual se indica a capacidade do Poder Judiciário de garantir os direitos fundamentais". Uma nova arena pública, alternativa ao circuito clássico "sociedade civil, partidos, representação e formação da vontade majoritária" é criada mediante a substituição desses procedimentos políticos de mediação por procedimentos judiciais, onde os indivíduos, grupos sociais e até mesmo partidos interpelam diretamente o Poder Judiciário.

Barbarói, Santa Cruz do Sul, n.43, p.<223-241>,jan./jun. 2015 
Não se limitando propriamente à política, na qual se têm reorganizado os clássicos mecanismos de representação, a judicialização se torna jurisdicionalização e se estende à regulação da sociabilidade e das práticas sociais, em que tradicionalmente a intervenção do Estado sempre esteve afastada. São os casos da emergência de novos direitos, como, por exemplo, dos direitos das crianças e adolescentes, dos ligados ao gênero, processos que se convencionou chamar de "jurisdicionalização das relações sociais".

Tudo e todos passaram a ser passíveis a uma resposta jurídica e de uma explicação qualquer, a partir dos códigos do Direito, que possam porventura justificar a si e as suas ações. A jurisdicionalização se dá em defesa de costumes e na busca por verdades, que é um dos componentes fundamentais da moral. Essas verdades podem se materializar nos códigos jurídicos, por meio das leis e dos aparatos que as sustentam (tribunais, prisões, penas alternativas, justiça terapêutica, entre outros), produzindo modos de vida moralizantes, revestidos pela doutrina do juízo.

Como salientado anteriormente, cada vez mais assistimos às pessoas recorrendo ao Judiciário para a resolução dos diferentes conflitos que encontram em seu dia a dia, de que pode ser exemplo o número crescente de processos, nas mais diversas áreas. Tal fato é efeito de uma "democratização do Poder Judiciário", movimento que vai ao encontro do que o italiano Mauro Cappelletti denomina “[...] implementação de formas mais democráticas, simples e rápidas de acesso à Justiça”" (VIANNA et al., 1999, p. 154) por parte da população. Ele tinha como expectativa que as pessoas tivessem suas práticas em relação à defesa de seus direitos alterada, favorecendo o cumprimento mais ágil e simplificado da norma ditada pela ordem jurídica.

Assim, no Brasil, temos efeitos dessas práticas como a aprovação da Lei 9.099, em 26 de setembro de 1995, a qual permitiu criar órgãos jurídicos para instrumentalizar o acesso à Justiça: os Juizados Especiais Cíveis e Criminais, que têm como objetivo a aproximação da sociedade e da lei. Eles atendem às encomendas por justiça de boa parte da população que, até então, encontrava-se alheia a esse tipo de prática (VIANNA et al., 1999). Todavia, essa justiça mais rápida se tornou mais fina e regular, mais constante e cada vez mais próxima do cotidiano de nossas existências.

Dessa maneira, Vianna e colaboradores (1999) também apontam que não só as pessoas recorrem cada vez mais ao Judiciário, a fim de que se cumpram as leis, assim como há uma expansão da capacidade normativa do sistema jurídico com a criação de leis que traduzam os interesses - individuais ou de grupos - em direitos. Estes armam o Judiciário, cada vez mais, de meios e modos para o exercício de uma intervenção na vida da população, inclusive em seu 
âmbito privado. Ou seja, reclamar por justiça parece simplesmente reduzir qualquer luta ao denuncismo e ao pedido de endurecimento penal, em mais e mais aberturas de processos por danos morais e a litígios infindáveis por tensões familiares, de trabalho, de vizinhos e entre amigos.

Lutar por reconhecimento social em face dos preconceitos e discriminações passou a ser quase um sinônimo de clamor pela lei e ordem, pela prisão e pelo recrudescimento penal. Todavia, acreditamos que nada disso é natural e que é possível pensar outras maneiras de luta e de agonística, as quais apostem mais na ética dos encontros do que nas leis. Mas, a contrapelo, cada vez menos ética opera os encontros e cada vez mais leis são aprovadas, penas são criadas e prisões são construídas. Acompanhamos o movimento de lei e ordem cada vez de forma mais intensa, nas décadas de 1970, 1980 e 1990, ao longo do século XX, momento em que movimentos sociais, além de lutarem pela democratização do Estado brasileiro, lutavam igualmente por emprego, terra, habitação, saúde, alimentação, educação, trabalho, entre outros.

Esses movimentos buscavam, ainda, mudanças legislativas que garantissem direitos, sobretudo para as minorias e para as populações marginalizadas (SILVA, 2001). E, entre os efeitos jurídicos dos movimentos sociais, temos: a promulgação da Constituição de 1988, que estabelece a criação da defensoria pública, "inaugurada" com o encargo de defender em juízo aqueles que não dispõem de recursos financeiros para arcar com os custos do processo, sem sacrificar o seu sustento e o de sua família, o que possibilitou uma maior aproximação desse público com o Sistema Judiciário.

Nesse sentido, narramos uma prática importante, a de assegurar um defensor público, mas, quando uma sociedade acredita e aposta cada vez mais na jurisdicionalização para fazer justiça, endurece mais as leis, encarcerando cada vez mais e com penas cada vez mais longas, é difícil pensar o que um defensor fará em meio a esse contexto de pressão para a condenação em massa dos que chegam aos bancos dos réus.

\section{Normas e leis, justiça e punição: disciplina, segurança e biopolítica na criminalização}

Segundo Nascimento (2012), sob a justificativa bem intencionada da proteção ou da prevenção, individualizam-se os desvios da norma, culpabiliza-se, vitimiza-se, criminaliza-se; enfim, pequenas e grandes mortificações do deixar morrer. E, aliada a essa lógica, encontra-se a da jurisdicionalização, que tem como funcionamento a produção massiva de discursos e 
práticas punitivo-criminalizantes, que no contemporâneo vão se espalhando no tecido social, produzindo, como já apontado por Foucault (2002), os racismos de Estado e de sociedade, estratégia de normalização que visa a garantir uma suposta superioridade e pureza da raça pela articulação dos saberes biológicos e dos biomédicos com os dispositivos jurídicoinstitucionais na produção da segurança.

Autores como Batista (2009) e Passetti (1999, 2006, 2009), lembram-nos que as formas que tomam nossas relações sociais, na atualidade, são engendradas em uma cultura punitiva, talvez só comparada com a época da inquisição e do nazismo, a qual prega o castigo e a vingança como forma de justiça social. O desejo de punir traz consigo o ranço de práticas históricas - como a violenta colonização de nosso país, a escravidão vivida de várias formas e a ditadura civil-militar (BATISTA, 2009).

Batista (2009) ainda aponta a figura da vítima como sendo um de seus componentes estratégicos. Por meio da vitimização, produz-se, como em uma simbiose, a criminalização de comportamentos e as formas de vida, a qual se entende materializar um "dos braços" da judicialização pela extensão punitiva a toda sociedade e não apenas ao campo penal. $\mathrm{Na}$ história da justiça penal, Passetti (1999) lembra-nos que quase nunca se pensa na justiça para a vítima. O que se quer, na maioria das vezes, é que se efetive um sistema de vingança.

Não obstante, a disciplina não se limita à gestão do crime e à indústria que o move. Ela é uma técnica de poder que fabrica os indivíduos, ao utilizar como plataforma uma anatomia política do corpo que se baseia em relações de poder-saber. A distribuição e a repartição superficial dos corpos, em um espaço determinado, os tornam úteis e dóceis, e a disciplina do espaço, do tempo, da vigilância, do exame e da observação hierárquica são mecanismos panópticos que operam em meio aberto, tanto entre os muros quanto intramuros. Nesse caso, mais do que leis, temos normas que possibilitam ir onde o Estado e seus aparelhos jurídicos não conseguem ir e atingir.

As normas colonizam o Direito, destaca Foucault (1979; 1996; 1999). Para ele, um direito normalizado e normalizador entra em cena, acionando outras máquinas e equipamentos, outras táticas e instrumentos, novas tecnologias de controle e vigilância que não estão restritas aos muros de uma escola, de uma fábrica e de um hospital, de uma prisão, apesar de por eles passar também.

A lei modula mais a pena em muros fechados, a norma modula mais a punição em meio aberto, a despeito de as duas se encontrarem nas duas situações, visto que se combinam na atualidade em quase todas as práticas sociais. Uma encarcera mais e a outra libera mais fluxos de produção com docilidade com poucos muros. A disciplina se vale da vigilância 
como um de seus mecanismos mais eficazes, e a lei da criminalização, do que a disciplina não conseguiu docilizar ou ainda da repartição do que é legal e do que é normalizante.

A vigilância produz docilidade e saúde, educação e assistência; segundo Candiotto (2012), engana-se quem pensa ser a sociedade disciplinar aquela na qual há apenas vigias nas torres, como se houvesse um acréscimo de guardas e disciplinadores. Pelo contrário, nas instituições de vigilância, precisou-se cada vez menos desses personagens. O poder disciplinar é econômico e tem positividade; ele se vale de espaços arquiteturais organizados de modo a incrementar e a facilitar a sensação de vigilância múltipla, detalhada e minuciosa de cada indivíduo que compõe seus interiores.

Assim, os hospitais, fábricas, famílias e escolas funcionam como microscópios do comportamento humano, ao possibilitarem a um único olhar tudo ver e vigiar, permanentemente. Candiotto (2012) ainda salienta que a economia do poder moderno tem, na invenção do Panóptico de J. Bentham, seu exemplo maior. Eis como Foucault o descreve:

Na periferia uma construção em anel; no centro, uma torre; esta é vazada de largas janelas que se abrem sobre a face interna do anel; a construção periférica é dividida em celas, uma atravessando toda a espessura da construção; elas têm duas janelas, uma para o interior, correspondendo às janelas da torre; outra, que dá para o exterior, permite que a luz atravesse a cela de lado a lado. Basta então colocar um vigia na torre central, e em cada cela trancar um louco, um doente, um condenado, um operário ou um escolar. Pelo efeito da contraluz, pode-se perceber da torre, recortando-se exatamente sobre a claridade, as pequenas silhuetas cativas nas celas da periferia. Tantas jaulas, tantos pequenos teatros, em que cada ator está sozinho, perfeitamente individualizado e constantemente visível. [...] O Panóptico é uma máquina de dissociar o par ver-ser visto: no anel periférico, se é totalmente visto, sem nunca ver; na torre central, vê-se tudo, sem nunca ser visto. (FOUCAULT, 1987, p. 165-166).

Percebemos que, a partir da vigilância, o poder se torna uma maquinaria múltipla, automática e anônima de punição generalizada se espraiar por toda sociedade e forjar subjetividades reivindicadoras de um clamor punitivo-penal desmedido. Trata-se do poder ao mesmo tempo indiscreto e discreto, pois se, de um lado, ele está em toda parte e sempre alerta, de outro, funciona sempre em silêncio. Ele pode, ainda, ser pensado como um poder do olhar calculado, porquanto a disciplina se faz funcionar por seus próprios mecanismos vigilantes, na regulação da ordem e da lei, no Estado Democrático de Direito.

O castigo usado como punição e tendo como objetivo a correção de condutas desviantes - os comportamentos agora, pela lei, são incriminados - é característico da sociedade denominada por Foucault como disciplinar. Instaura-se a norma, atribui-se a 
determinados comportamentos o status de "normais" e, consequentemente, a outros, que fogem à norma, o de "anormais". Aqueles que não se inscrevem na norma são punidos, a fim de que se reestabeleçam, atingindo o padrão estabelecido pela norma. Norma e lei se mesclam em normativa, legalidade e normalização, que se coadunam na judicialização intensa rumo à articulação com uma criminalização exacerbada.

E, se, cada dia mais, somos convocados a participar do Judiciário, intensificamos as penalidades dos juízes e nos tornamos juízes do cotidiano: em nossas casas, usamos o castigo como forma de ensino para nossos filhos, adotando-o nos momentos em que não praticam as atitudes esperadas. Os castigos podem ser físicos, mas que nem sempre são; nas escolas, os mestres administram aos seus alunos penalizações como notas baixas, por exemplo, que o farão repetir o ano, por não terem conseguido reproduzir o conteúdo ensinado na prova, como se esperava que eles fizessem; algumas escolas, ainda, têm a "salinha do pensamento" e/ou "o cantinho da disciplina", local reservado para que o aluno fique "refletindo" sobre algo julgado como errado e como indisciplina, que pode até ser registrado nos tais livros de ocorrência escolares. Nesse âmbito, Bujes (2010) e Passetti (2009) comentam:

A elaboração de leis, ao longo do século XVI e XVII, para regular a conduta das populações pobres e, ao mesmo tempo, definir recursos e organizar formas para assisti-las teve presente uma preocupação específica com as crianças desses segmentos. Embora a interpretação do imperativo moral de socorrer os pobres muitas vezes suscitasse polêmica, tinha-se especial atenção para com as crianças, uma vez que não socorrê-las poderia se traduzir no perigo de que se habituassem a uma vida de mendicidade. As medidas geralmente preconizadas eram as do envio das crianças para a escola ou a uma instituição de abrigo, o arranjo de uma posição como aprendizes ou sua colocação como domésticas. (BUJES, 2010, p. 164).

Educar é cultivar o espírito: formá-lo e fazê-lo adquirir cultura. É transmitir conhecimento, erudição, adestramento e domesticação a cada pessoa para torná-la obediente a comandos que zelam pelo culto e cultivo de uma moral superior. Toda a educação para a obediência requer ameaça e uso de castigos que funcionam como prevenções gerais à manutenção do equilíbrio da sociedade. [...] A ameaça e o uso de castigos, enfim, geram o medo necessário para o governo dos pais, dos governantes e dos procedimentos disciplinares. (PASSETTI, 2009, p. 162).

São essas as formas de socialização que, desde cedo, apresentamos às nossas crianças. Elas são expostas muito novas a essa cultura do castigo, que passa a ser vista, depois de um tempo, como algo natural, uma prática normal. Tornar cada cidadão um vigilante do direito tem produzido relações de ameaça sustentadas no julgamento sistemático entre as pessoas. 
Todos nos tornamos juízes; todos nós julgamos, punimos e condenamos, ou pedimos a pena; acreditamos na pena e modulamos as punições.

Essa vontade de julgar, de sentenciar, apenas expressa o medo em enfrentar o desconhecido, o surpreendente, o vivido. É comum ouvir das pessoas: "E agora? O que fazer? Deixa como está? Não vai acontecer nada?". Nessa pressa em deliberar uma sentença, perde-se o que um acontecimento, mesmo que trágico ou doloroso, pode trazer de diferente, de transformador, muitas vezes a despeito de racionalizações ou temporalidades. (AUGUSTO, 2009, p.12).

E o principal poder emergente desse conjunto de "[...] movimentos punitivos vai ser a legitimação da intervenção moral” (BATISTA, 2009, p. 154), por meio da invasão do Estado penal nas relações privadas, como nas de família ou de vizinhança, havendo o confisco dos pequenos conflitos por parte do Poder Judiciário - outro braço que entendemos ser o da judicialização/criminalização. Veremos, por conseguinte, despontar a figura do juiz em quase todos os aspectos da vida social. Cada vez mais um grande contingente de pessoas tem procurado privilegiadamente o sistema de justiça, que é visto como sistema incontestável de verdade, para a resolução dos mais variados conflitos.

Benevides e Passos (2005) fazem uma análise do Direito da modernidade e afirmam que ele é constituído no contrato social, que convoca o cidadão a assiná-lo, pressupondo o perigo das massas. Assim, entregamo-nos a uma instância transcendente que assegura o controle social por meio de um Estado representativo e policial, que, ao apoiar-se em verdades absolutas (contidas nos códigos prescritivos, normalizadores), seguem pelos caminhos dos estados de dominação (RODRIGUES; TEDESCO, 2009).

Sob essa égide, Bujes (2010) analisa que, desde o século XIX, por exemplo, como o controle sobre as crianças vem-se aprofundando, pois um discurso regulamentador tem possibilitado uma efetuação de diagnósticos, a proposição de medidas, a previsão de resultados, colocando em ação um princípio de visibilidade obrigatória que funciona como assujeitamento. E, dessa forma, a autora problematiza a noção de risco, presente tanto nos discursos do cotidiano como nas políticas para a infância, para indicar sua associação a um tipo de racionalidade que orienta formas específicas de exercício do poder que se endereçam ao campo da atenção à infância, criticando a disciplina como forma de exercício da dominação, como estratégia para extrair dos corpos vigiados e examinados o máximo de utilidade e de obediência e, do mesmo modo, um conjunto de saberes sobre eles. 
Em acréscimo, segundo Lara, Guareschi e Hüning (2010), o processo de investimento na infância pelas práticas de poder incitou a construção de diferentes saberes especializados sobre as crianças. Muitas disciplinas passariam a produzir verdades sobre a criança: Psicologia, Pedagogia, Direito, Medicina, Pediatria etc. O investimento do saber médico na criança foi um modo de diminuir a mortalidade infantil por meio de intervenções de formação moral, física e intelectual das crianças, de maneira a ditar regras e normas de preparo e aperfeiçoamento dos futuros "homens da sociedade".

A noção de risco e as práticas dela derivadas estão associadas a um deslocamento da sociedade disciplinar para outra, que Foucault (2008a) denominou "sociedade de segurança". Os mecanismos de segurança operam uma proliferação/fabricação de riscos que são confrontados com uma forma de normalização a qual parte de uma definição do normal e do anormal, segundo curvas de normalidade.

Para adensar essa discussão, trazemos ao debate uma concepção de moral definida por Foucault (1985b). Ao tratar de moral, salienta que essa palavra carrega em si ambiguidade, podendo ser compreendida de diferentes maneiras. O primeiro entendimento de moral, segundo ele, refere-se a "[...] um conjunto de códigos e regras de ação propostas aos indivíduos ou grupos por intermédio de aparelhos prescritivos diversos" (p. 26), que podem ser ensinados e passados explicitamente ou serem transmitidos de maneira difusa.

Alude-se a um código moral. Ele aparece explicitamente nas leis, que determinam o que o indivíduo deve ou não fazer; nos tribunais, nas sentenças dos juízes, que impõem (baseado nas leis, conjugadas aos atos dos que eles julgam) qual penalidade deve ser cumprida, entre outras situações. Para Foucault (1985b), porém, moral ainda pode ser concebida como “[...] o comportamento real dos indivíduos em relação às regras e valores que lhes são propostos [...], a maneira [...] pela qual eles obedecem ou resistem a uma interdição ou prescrição, pela qual respeitam ou negligenciam um conjunto de valores [...]” (p. 26). A isso ele chama de moralidade dos comportamentos. Ou seja, há outro componente na moral, que diz respeito à aceitação ou não, na vida, dos códigos ensinados de forma explícita ou implícita; uma margem entre o fazer e o código que os indivíduos e os grupos forjam.

Nessa perspectiva, teríamos até agora dois entendimentos de moralidade, conforme Foucault: a dos códigos constituídos culturalmente e a das margens de aceitação ou não a esses códigos. Contudo, ainda há outro elemento da moral que o autor chama de "determinação da substância ética”. Essa concerne à "[...] maneira pela qual se deve constituir a si mesmo como sujeito moral". Dado um código, há "diferentes maneiras de 'se conduzir"”, isto é, há diferentes modos de sujeitar-se, de “[...] estabelecer relação com a regra e se 
reconhecer como ligado à obrigação de pô-la em prática" (FOUCAULT, 1985b, p. 27). Pensamos, pois, que, diante de uma penalidade oferecida pelo jurídico, há diferentes formas de constituir-se enquanto apenado, técnico, juiz de direito etc. A essa moral o autor dá o nome de ética.

Em compensação, pode-se muito bem conceber morais cujo elemento forte e dinâmico deve ser procurado do lado das formas de subjetivação e das práticas de si. A ênfase é dada, por conseguinte, às formas das relações consigo, aos procedimentos e às técnicas pelas quais são elaboradas, aos exercícios pelos quais o próprio sujeito se dá como objeto a conhecer, e às práticas que permitem transformar seu próprio modo de ser (FOUCAULT, 1985b, p. 30).

Michel Foucault (1985a) nos dá ferramentas para pensarmos as diversas formas em que se manifestam a judicialização e criminalização. Quando fala de poder, não traz como Aparelho de Estado ou como algo que alguns detêm e outros não, mas como “[...] multiplicidade de correlações de força [...] o jogo que, através de lutas e afrontamentos incessantes se transforma, reforça, inverte" (p. 88-89), como uma ação sobre outra ação, ou ainda, "[...] o nome dado a uma situação estratégica complexa numa sociedade determinada" (p. 89), que pode se instrumentalizar nos estabelecimentos estatais, nas leis, entre outros. Ainda de acordo com ele, a sociedade disciplinar está nascendo. Nela, o indivíduo não cessa de passar de um espaço fechado para outro, cada um com seu ritual específico, mas todos com a mesma lógica: disciplinar os corpos, tornando-os dóceis e úteis.

Consequentemente, é em tal sociedade que as "instituições de sequestro" emergem, no século XIX, para organizar a massa de indivíduos pobres, decorrentes do processo de industrialização. Na opinião de Foucault (1996), tais instituições são aquelas criadas para vigiar os indivíduos e os grupos, tendo por finalidade a inclusão e a normalização. Segundo ele, tornou-se imprescindível dispor as "coisas", arrumá-las, para que se pudessem conduzir as condutas, governar. A docilização e a desqualificação dos corpos que são disciplinados nessas instituições produzem ao mesmo tempo o aumento da força produtiva e a diminuição da força política, de contestação.

Há uma importância crescente assumida pela atuação da norma. Um poder que tem a tarefa de se encarregar da vida terá necessidade de mecanismos contínuos, reguladores e corretivos, pois distribuirá os vivos em um domínio de valor e utilidade. "Uma sociedade normalizadora é o efeito histórico de uma tecnologia de poder centrada na vida" (FOUCAULT, 1985a, p.190). As instituições de sequestro teriam a função de cuidar da normalidade dos indivíduos, denotando a concepção de uma natureza, de uma índole que terá de ser controlada para garantir a ordem. Sobre o caráter da disciplina Foucault (2008b) reflete: 
Tomemos agora a disciplina. [...] Ela os decompõem [indivíduos, lugares, operações, gestos, etc.) em elementos que são suficientes para percebê-los, de um lado, e modificá-los, de outro. [...] a disciplina classifica os elementos assim identificados em função de objetivos determinados. [...] a disciplina estabelece as sequências ou as coordenações ótimas [...]. [...] a disciplina estabelece os procedimentos de adestramento progressivo e de controle permanente e, enfim, a partir daí, estabelece a demarcação entre os que serão considerados inaptos, incapazes e os outros. Ou seja, é a partir daí que se faz a demarcação entre o normal e o anormal. [...] Em outros termos, o que é fundamental e primeiro na normalização disciplinar não é o normal e o anormal, é a norma. [...] [o que] acontece nas técnicas disciplinares se trata mais de uma normação do que de uma normalização. (FOUCAULT, 2008b, p. 74-76).

Ademais, Foucault (1985a) nos aponta outro foco de exercício desse poder, constituído em meados do século XVIII e assumido por meio de intervenções e controles reguladores das populações. Pondera que é um campo mais amplo que “[...] centrou-se no corpo-espécie, no corpo transpassado pela mecânica do ser vivo e como suporte dos processos biológicos" (p.131), o que ele denominou biopolítica das populações.

Com a biopolítica e a concepção da regularidade dos fenômenos populacionais, as medidas tomadas pelo Estado não têm mais o caráter definitivo das leis, mas se adaptam aos resultados previsíveis, por meio dos mecanismos de segurança, os quais apontam estimativas, probabilidades. Além da classificação entre normais e anormais, há o delineamento de diferentes curvas de normalidade. Temos, assim, uma gradação de normalidade, e os que estão distantes do modelo proposto, mas ainda são normais, passam a ser considerados perigosos. A sociedade teme a diferença; Lara, Guareschi e Hüning (2010) cooperam com essa discussão, destacando:

A partir da segunda metade do século XVIII, desenvolveu-se outra tecnologia de poder, que não excluía a técnica disciplinar, mas a integrava e modificava. Esse poder não mais atingiria apenas o corpo individual, mas a vida dos homens, o homem enquanto ser vivo e espécie. Esse poder tomaria a população, e não apenas o indivíduo como alvo de governo e como sujeito de necessidades. A racionalidade do governo passou a abarcar os processos disciplinares dos corpos e os processos regulamentares da vida e colocou-se como regime de verdade que instituiu modos de ser e estar no mundo - uma biopolítica da população. (LARA; GUARESCHI; HÜNING, 2010, p. 78).

Nessa estratégia do poder, a vida passou a ser gerida em todos seus âmbitos, garantida, sustentada, reforçada e multiplicada ao longo de todo o seu desenvolvimento. A morte, por ser o momento em que a vida escapa, tornou-se o limite de intervenção do poder (LARA; 
GUARESCHI; HÜNING, 2010). Os mecanismos disciplinares integram-se aos da biopolítica e, segundo Foucault (1985a), esses são os dois polos do chamado biopoder, que atingiu seu auge no século XIX. É um poder cuja função mais elevada é investir sobre a vida, de cima a baixo, nutrindo-se dela, a fim de perpetuá-la.

Nesse sentido, o investimento sobre a vida é ao mesmo tempo individualizante (atuando no corpo, por meio das disciplinas) e totalizante (com o controle da dinâmica das populações, ocupando-se das estatísticas, das taxas de natalidade e mortalidade, níveis de saúde etc.). O paradoxo na biopolítica do fazer viver e deixar morrer cumpre a função de eliminação dos grupos produzidos como inimigos da sociedade, da criminalização dos que são colocados na miséria e indigência tais como párias a isolar permanentemente como fossem refugiados urbanos. Se a vida entra em cena no Direito para ser protegida isso não significa que será a vida de toda população a ser garantida, pois, uns se tornam mais protegidos que outros, na discriminação social e econômica, no liberalismo contemporâneo.

Portanto, faz-se um controle sobre todos e sobre cada um. Dessa forma, não só há uma intervenção na maneira de estar vivo, mas também há uma intervenção que dita como se deve viver (FOUCAULT, 1999). No caso específico da biopolítica, a judicialização e a criminalização se tornaram relevantes em termos de economia política, mundializada e no plano dos contratos de empresariamento da vida que se tornam cada vez mais recorrentes, na medida em que somos incentivados a contratar e a estabelecer cláusulas para os chamados empreendimentos cotidianos.

Os sujeitos empreendedores vão ganhando centralidade política quanto aos sujeitos de direitos; esse acontecimento traz mais um elemento de análise importante para pensarmos a judicialização e a criminalização da vida, porque explicita o entrecruzamento dos direitos com a economia de maneira mais acirrada. Um exemplo é o cálculo, no PIB de um país, das violações de direitos e das violências e de quem vai pagar essa conta, resguardando-nos da violação e prevenindo a violência e/ou o cuidar depois de ela ocorrer.

Em praticamente todo o curso Nascimento da Biopolítica (2008b), Foucault analisa esses acontecimentos relacionados à economia neoliberal e em uma sociedade de direitos. Quanto mais empresários, menos direitos sociais e mais direitos comerciais e regulamentação pública das políticas privadas, diante dos danos e prejuízos, processos e disputas jurídicas.

\section{Conclusões}

Deve-se ter em perspectiva que a criminalização das condutas cotidianas, a judicialização da vida não seja a aposta única e intensiva que fazemos, em tempos sombrios e 
inflacionados de subjetividades reacionárias, ávidas por clamores punitivistas e por posturas fundamentalistas como essas formas de viver fosse dar conta das tensões de uma sociedade cada vez mais complexa.

Assim, para concluir, gostaríamos de ressaltar que não podemos reduzir nossas vidas aos processos jurídicos, judicializando e criminalizando nossa existência; uma vez que deve haver um mundo para além do processo judicial como tática de lidar com as tensões advindas das disputas sociais e das desigualdades econômicas liberais, em que haja possíveis no campo ético que nos permitam romper barreiras, conversar, pensar, inventar, estabelecer novos parâmetros e referenciais de pensamento e atuação, além de estratégias de um direito não reduzido à lei e à ordem.

\title{
REFLECTIONS REGARDING PROCESSES JUDICIALIZATION AND CRIMINALIZATION IN CONTROL THE CONTEMPORARY
}

\begin{abstract}
The practical uses of the judiciary to deal with the stress in have expanded in recent years; in a process judicialization and criminalization of life. We note a relationship between society and the Judiciary ruled in search of expanding laws and criminal typification as ways of governing conduct in the field of a security-legalism. The judiciary seems to become a kind of unique arena to which converge all sorts of tension and disagreement, and the laws thus become the language of this mediation. But also a description and analysis approach that operates by historical standards of the law in the courts of the norm. Thus, we seek in this brief analysis, reflect on these issues, proposing analyze these control devices which intensify today, and causing new forms of subjection.
\end{abstract}

Keywords: Judicialization and Criminalization. Laws and penalties. Security and control. Sovereign Power. Court rules.

\section{REFLEXIONES EN RELACIÓN CON LOS PROCEDIMIENTOS JUDICIALIZACIÓN Y EN EL CONTROL DE PENALIZACIÓN CONTEMPORÁNEO}

\begin{abstract}
Resumen
La apelación a las prácticas judiciales para hacer frente a las tensiones, se han ampliado en las últimas décadas, en el proceso de legalización y la criminalización de la vida. Observamos uma relación entre la sociedad y el poder judicial gobernado en la búsqueda de la expansión de las leyes penales y tipificaciones como formas de regir la conducta en el ámbito de la seguridad-legalismo. El poder judicial parece convertirse en una especie de escenario único para que convergen todo tipo de tensión y desacuerdo, y las leyes, por lo tanto, se convierten en el lenguaje de esta mediación. Pero también nos acercamos a una descripción y análisis
\end{abstract}


histórico que opera la normalización de la ley en los tribunales de la norma. De este modo, se busca, en este breve análisis, reflexionar sobre estas cuestiones, proponiendo analizar estos dispositivos de control que intensifican hoy y las nuevas formas de provocación de sujeción.

Palabras clave: Legalización y la criminalización. Leyes y sanciones. Seguridad y control. El poder soberano. Corte de las normas

\section{Referências}

AUGUSTO, A. Juridicialização da vida ou sobrevida? Mnemosine, n.1, v.5, p. 11-22, 2009.

BATISTA, V.M. Criminologia e Política Criminal. In: Passagens. Revista Internacional de História Política e Cultura Jurídica. Rio de Janeiro: n 2, v. 1, p. 20-39, 2009.

BENEVIDES, R.; PASSOS, E. A humanização como dimensão pública das políticas de saúde. Ciência e Saúde Coletiva, n.3, v.10, p 561-571, 2005.

BUJES, M. I. E. Infância e Risco. Educação e Realidade, Porto Alegre, v. 35, n. 3, p. 157$174,2010$.

CANDIOTTO, C. Disciplina e segurança em Michel Foucault: a normalização e a regulação da delinquência. Psicologia \& Sociedade, 24 (n. spe.), 18-24, 2012.

CAPPELLETTI, M. Juízes Legisladores? Porto Alegre: Sérgio Antonio Fabris, 1993.

FOUCAULT, M. Aula $1^{\circ}$ de Fevereiro de 1978. In: Segurança, território, população. São Paulo: Martins Fontes, 2008a, p. 117-154.

FOUCAULT, M. Nascimento da Biopolítica. São Paulo: Martins Fontes, 2008b.

FOUCAULT, M. Em defesa da sociedade. São Paulo: Martins Fontes, 2002.

FOUCAULT, M. Aula 17 de março de 1976. In: Em defesa da sociedade. São Paulo, Martins Fontes, 1999, p. 285-315.

FOUCAULT, M. A verdade e as formas jurídicas. Rio de Janeiro: Nau, 1996.

FOUCAULT, M. Vigiar e punir. 5. ed. Petrópolis, RJ: Vozes, 1987.

FOUCAULT, M. Método. In: História da sexualidade I: a vontade de saber. Rio de Janeiro: Graal, p. 102-113, 1985a.

FOUCAULT, M. Moral e prática de si. In: História da sexualidade II: o uso dos prazeres. Rio de Janeiro: Graal, p. 26-31, 1985 b.

LARA, L.; GUARESCHI, N. M. F.; HÜNING, S. M. Saúde Pública e Saúde Coletiva: condições de emergência no cuidado da saúde da criança. Mnemosine, v. 1.6, n. 2, p. 77-96, 2010 .

NASCIMENTO, M. L. (Abrigo, pobreza e negligência: percursos de judicialização. Psicologia \& Sociedade, 24 (n. spe.), 39-44, 2012. 
PASSETTI, E. Sobre sociedade de controle, educação e fluxos. In: TEDESCO, S.;

NASCIMENTO, M. L. (Org.). Ética e subjetividade: novos impasses no contemporâneo.

Porto Alegre: Sulina, 2009, p. 156-168.

PASSETTI, E. Ensaio sobre um abolicionismo penal. Verve. 9, p. 83-114, 2006.

PASSETTI, E. Sociedade de controle e abolição da punição. São Paulo em Perspectiva. v.13 n. 3, 1999.

PRADO FILHO, K. Uma breve genealogia das práticas jurídicas no Ocidente. Psicologia \& Sociedade, 24 (n. spe.), 104-111, 2012.

RODRIGUES, C.; TEDESCO, S. Por uma perspectiva ética das práticas de cuidado no contemporâneo. In: TEDESCO, S.; NASCIMENTO, M. L. (Org.). Ética e subjetividade: novos impasses no contemporâneo. Porto Alegre: Sulina, 2009, p. 74-95.

SANTOS, B. S. et al. Os Tribunais nas sociedades contemporâneas. Revista Brasileira de Ciências Sociais, n. 30, ano 11, 1996.

SILVA, C.A. Promotores de justiça e novas formas de atuação em defesa de interesses sociais e coletivos. Revista Brasileira de Ciências Sociais, n. 45, v. 16, p. 128-144, 2001.

VIANNA, L. W. et al. A Judicialização da política e das relações sociais no Brasil. Rio de Janeiro: Revan, 1999.

VIANNA, L. W. et al. Corpo e alma da magistratura brasileira, $3^{\mathrm{a}}$ ed, Rio de Janeiro: Revan, 1997.

Data de recebimento: 11/10/2013

Data de aceite: $26 / 06 / 2014$

\section{Sobre os autores:}

Cristiane Freitas da Silva é Formada em Serviço Social pela UFPA. Mestre em Psicologia/UFPA. Endereço eletrônico: cris.ssocial08@ gmail.com

Flávia Cristina Silveira Lemos é Professora adjunta IV em psicologia social, na Universidade Federal do Pará - UFPA. Endereço eletrônico: flaviacslemos@gmail.com

José de Araújo Brito Neto é Advogado/UFMA. Mestre em Psicologia/UFPA. Endereço eletrônico: joseb_neto@hotmail.com

Michelle Ribeiro Côrrea é psicóloga/UFPA. Advogada/UNAMA. Psicóloga no Tribunal de Justiça do Pará/PA. Endereço eletrônico: correamichelle@ hotmail.com

Amanda Pereira de Carvalho Cruz é Psicóloga/UFPA. Mestre em Psicologia/UFPA. 
Paulo de Tarso Ribeiro de Oliveira é Psicólogo/UFPA. Mestre e Doutor em Saúde Coletiva pela ENSP/FIOCRUZ. Prof. adjunto IV em Psicologia do Trabalho/UFPA. Endereço eletrônico: pttarso@gmail.com 